\title{
Re: Clinical and Genomic Characterization of Low-Prostate- specific Antigen, High-grade Prostate Cancer
}

Mahal $\mathrm{BA}^{1}$, Yang $\mathrm{DD}^{2}$, Wang $\mathrm{NQ}^{3}$, Alshalalfa $\mathrm{M}^{3}$, Davicioni $\mathrm{E}^{3}$, Choeurng $\mathrm{V}^{3}$, Schaeffer $\mathrm{EM}^{4}$, Ross $\mathrm{AE}^{5}$, Spratt $\mathrm{DE}^{6}$, Den $\mathrm{RB}^{7}$, Martin $\mathrm{NE}^{8}$, Mouw KW', Orio $\mathrm{PF}^{8}$, Choueiri TK', Taplin $\mathrm{ME}^{9}$, Trinh $\mathrm{QD}^{10}$, Feng $\mathrm{FY}^{11}$, Nguyen $\mathrm{PL}^{12}$

${ }^{1}$ Harvard Radiation Oncology Program, Boston, USA; Harvard Medical School, Boston, USA

${ }^{2}$ Harvard Medical School, Boston, USA

${ }^{3}$ GenomeDx Biosciences, Vancouver, British Columbia, Canada

${ }^{4}$ Northwestern University Faculty of Medicine, Department of Urology, Chicago, USA

${ }^{5}$ James Buchanan Brady Urological Institute, Johns Hopkins Medical Institutions, Baltimore, USA

${ }^{6}$ Michigan University, Department of Radiation Oncology, Ann Arbor, USA

${ }^{7}$ Sidney Kimmel Medical College at Thomas Jefferson University, Department of Radiation Oncology, Philadelphia, USA

${ }^{8}$ Harvard Medical School, Boston, USA; Brigham and Women's Hospital/Dana-Farber Cancer Institute, Clinic of Radiation Oncology Boston, USA

${ }^{9}$ Harvard Medical School, Boston, USA; Brigham and Women's Hospital/Dana-Farber Cancer Institute, Clinic of Medical Oncology, Boston, USA

${ }^{10}$ Harvard Medical School, Boston, USA; Brigham and Women's Hospital, Clinic of Urological Surgery, Boston, USA

${ }^{11}$ University of California at San Francisco, Departments of Radiation Oncology, Urology, and Medicine and Helen Diller Family Comprehensive Cancer Center, San Francisco, USA

${ }^{12}$ Harvard Medical School, Boston, USA; Brigham and Women's Hospital/Dana-Farber Cancer Institute, Clinic of Radiation Oncology, Boston, USA

Eur Urol 2018 Feb 22. pii: S0302-2838(18)30098-8. doi: 10.1016/j.eururo.2018.01.043.

\section{EDITORIAL COMMENT}

Prostate-specific antigen (PSA) is typically elevated in high-grade prostatic adenocarcinoma. However, some patients present with high-grade disease and low PSA. Patients presenting with neuroendocrine prostate cancer, which is an aggressive entity that does not respond to hormone therapy also typically have low PSA values. In order to investigate the clinical implications and genomic features of low-PSA, high-grade disease, the authors performed a retrospective study of clinical data from the National Cancer Data Base, Surveillance, Epidemiology and End Results program, and genomic data from the Decipher Genomic Resource Information Database.

For Gleason 8-10 disease, using PSA 4.1-10.0 $\mathrm{ng} / \mathrm{mL}(\mathrm{n}=38.719)$ as referent, the distribution of PCSM by PSA was U-shaped, with an adjusted hazard ratio of 2.70 for PSA $\leq 2.5 \mathrm{ng} / \mathrm{mL}(\mathrm{n}=3862, \mathrm{p}<0.001)$ versus 1.97, 1.36, and 2.56 for PSA of 2.6-4.0 $(\mathrm{n}=4199), 10.1-$ $20.0(n=17.372)$, and $>20.0 \mathrm{ng} / \mathrm{mL}(\mathrm{n}=16.114)$, respectively. For Gleason 8-10 tumors, PSA $\leq 2.5 \mathrm{ng} / \mathrm{mL}$ was associated with higher expression of neuroendocrine/small-cell markers compared to $>2.5 \mathrm{ng} / \mathrm{mL}$ ( $p=0.046)$, with no such relationship for Gleason $\leq 7$ disease.

These results show that low-PSA, high-grade disease is associated with a more than two-fold higher risk of prostate cancer death relative to NCCN high-risk/very high-risk disease, with a large number of deaths occurring within a short period after diagnosis. The authors argue that the clinical and genomic data from this study strongly suggest that low-PSA, high-grade prostate cancer is a clinically and biologically unique entity that is associated with poor prognosis and that may not respond well to androgen deprivation therapy. Thus, the findings of this study pave the way for further studies and possibly for developing modified risk classifications and alternative treatment approaches such as early chemotherapy for patients with low-PSA, high-grade prostate cancer.

Özgür Yaycıŏlu, MD, FEBU

๑Copyright 2018 by the Association of Urological Surgery / Journal of Urological Surgery published by Galenos Publishing House. 